__ \& FrANKE, K. J. (1985) Sued and non-sued physicians' self-reported reactions to malpractice litigation. The American Journal of Psychiatry, 142, 437-440.

-, Pyskoty, C. E. \& Nelson, A. (1988) Physicians on trial-self-reported reactions to malpractice trials. The Western Journal of Medicine, 148, 358-360.

Foulkes, E. C. (1987) You and malpractice. Stress: V. A death in the family. Journal of the Medical Association of Georgia, 76, 115-116.

READING, E. G. (1986) The malpractice stress syndrome. New England Journal of Medicine, 83, 289-290.

St Paul Fire and Marine Insurance Company (1986) Physicians' and Surgeons' Update: A Special Report-Vol. 3. St Paul, Minn.

\section{Psychiatry in the private sector}

DeAR SIRS

Saeed Islam's letter (Psychiatric Bulletin, June 1990, 14,370 ) on psychiatry in the private sector cannot be allowed to pass unchallenged as it raises important issues in the context of the current political climate. The letter purports to be a brief research report demonstrating that "the Priory Hospital ... is prepared and able to meet the needs of a representative sample of psychiatric patients". It does no such thing, but is in fact a brief demonstration of the disingenuous art of false inference.

The study attempts to evaluate the clinical activity of the Priory Hospital (private) and the Charing Cross Hospital (NHS) by comparing crude ICD-9 diagnoses of patients admitted as psychiatric emergencies. It ignores the fact that the objectives of these two institutions are completely different and that they serve demographically dissimilar populations. It compounds this error by implying that the activity of a professorial department in a large London teaching hospital is similar to the activity of NHS psychiatric units generally. It gives no information as to how patients were "surveyed" or sampled, whether retrospectively or prospectively, how emergency was defined or how, when and by whom diagnosis was made. There are no data on secondary diagnoses, chronicity or severity of illness or on demographic characteristics of the two populations. Even if this information were available, admission data are widely recognised to be misleading in service evaluation, particularly in the absence of supplementary data such as length of stay.

The accompanying table is strange: $\mathrm{N}=53$ for the Priory Hospital but there is no figure given for the Charing Cross Hospital. Percentages for the Priory are lent an air of spurious accuracy by being taken to the first decimal place, but when more closely examined do not correspond in any way to whole numbers of patients. In contrast the figures for the Charing Cross are rounded to a whole percentage point. The letter provides no valid evidence to support its conclusions which are firmly stated as above.
The publication of this letter in the Psychiatric Bulletin will be taken to support those who within central government and NHS management are attempting to dismantle comprehensive integrated district psychiatric services and replace them with a quasi commercial service on the disastrous US model. Patient populations in private psychiatry differ greatly from those seen by NHS services, a reason frequently given by psychiatrists for working privately.

Private psychiatry has usually recognised itself to be "complementary" and marginal to the NHS, and in fact is irrelevant to the needs of the largest and most vulnerable group of psychiatric patients.

I trust that in future material such as Dr Islam's letter will be clearly marked "advertisement feature", allowing it to be scrutinised by the Advertising Standards Authority, by whose criteria it will undoubtedly be found wanting.

Royal Liverpool Hospital

Rob POOLE Liverpool L7 8XP

\section{DeAr SirS}

Dr Islam (Psychiatric Bulletin, June 1990, 14, 370 371) makes a feeble attempt to compare favourably the emergency services provided by a private (Priory) Hospital with that of a NHS (Charing) Hospital only on the basis that the diagnostic mix of 53 patients admitted to Priory Hospital was not significantly different from that of an unspecified number of patients admitted to Charing Cross Hospital.

He does not make any attempt to consider the other more important variables like the outcome of these admissions and percentages of patients who are not offered admission on the basis of their inability to pay. There is little in his article which makes me reconsider my opinion that the "private sector caters largely for affluent, neurotic individuals ..." I too hope that Dr Islam will be able to conduct a more meaningful study which I am sure will confirm the common belief among his fellow psychiatrists about the private sector.

\section{Ashworth Hospital \\ Parkbourn, Maghull \\ Merseyside $\mathrm{L3I} 1 \mathrm{HW}$}

\section{DeAr SirS}

I would like to respond to Dr Rob Poole's criticisms by pointing out that these would have been appropriate if I had assumed that my "brief research report" was a scientific paper.

In fact, I wrote a letter to the Psychiatric Bulletin, (June 1990, 14, 370) providing the readers with my clinical observations regarding the similarities between the diagnostic groups of the patients seen at 